\title{
Morphological study of plantaris muscle in cadavers and its clinical significance
}

\author{
Seema Prakash", Parveen Ojha ${ }^{2, *}$ \\ ${ }^{1}$ Professor, ${ }^{2}$ Assistant Professor, Dept. of Anatomy, R.N.T. Medical College, Udaipur, Rajasthan, India
}

*Corresponding Author:

Email: drparveena@yahoo.com

\begin{abstract}
Plantaris muscle though a vestigial muscle and absent in $10 \%$ of cases still has a diagnostic and clinical importance e.g., of its being an isolated cause of tennis leg. This study was done on 50 lower limbs of 25 adult cadavers for morphology and prevalence of plantaris muscle in our region. We have observed absence of plantaris muscle in about $26 \%$ of limbs and both belly and tendon of the plantaris muscle had a wide variation in its length and width. In two of the limbs double head of origin of muscle was seen.
\end{abstract}

Keywords: Double Head, Plantaris, Vestigial.

Received: $18^{\text {th }}$ August, 2017

\section{Introduction}

Plantaris muscle takes origin from lower part of the lateral supracondylar line of femur and oblique popliteal ligament of the knee joint. Its $7-10 \mathrm{~cm}$ long belly ends in a slender tendon which runs obliquely between gastrocnemius and soleus and fuses with calcaneal tendon or inserts with it. It gets its nerve supply from nerve to lateral head of gastrocnemius, a branch of tibial nerve. Sometimes it may have double origin or its tendon may merge with flexor retinaculum or with fascia of the leg. ${ }^{1}$ As reported in literature, it is absent in $10 \%$ of cases and has been found to be an isolated cause of tennis leg. Though believed to be a vestigial muscle in human beings, it still has a wide clinical and diagnostic importance. Hence correct knowledge of its presence and appearance is important to avoid error in day to day clinical practice by radiologists, orthopaedists and physiotherapists.

\section{Materials and Methods}

The study was done at R.N.T.Medical College, Udaipur on 50 lower limbs of 25 embalmed cadavers (19 males and 6 females) for a period of two years (2015-2017). All the cadavers were of the age group 50-60 years. None of them had any congenital anomalies. Limbs with any scar mark due to injury or surgery were excluded from the study. Dissection of posterior compartment of thigh and leg was done according to the steps described in Cunningham's Manual of Practical Anatomy. ${ }^{2}$ Measuring tape and vernier calipers were used to measure the length and breadth respectively of the muscle and its tendon respectively.

\section{Observations}

Detailed morphological study of plantaris muscle was done and following parameters were recorded-

Origin and insertion of the muscle. Length of muscle belly and tendon were measured with the help of measuring tape and were recorded on a paper. Thickness of muscle belly and its tendon were measured with the help of vernier callipers. Any variation in origin or insertion was also recorded and photographed.

\section{Results}

Total lower limbs studied-50 (25 Cadavers-19 Males and 6 Females)

The muscle in 48 lower limbs originated normally from the lower part of lateral supracondylar line of femur. (Fig.1) In two cases variations in origin of muscle were seen:

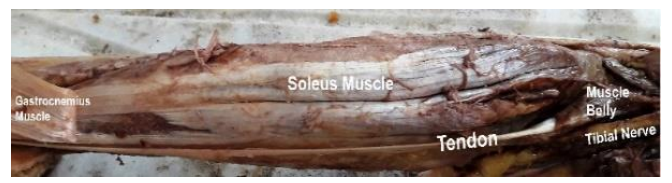

Fig. 1: Plantaris Muscle

In cadaver no. 6 (Fig. 3) Double head of origin of plantaris muscle was noticed in right lower limb. One head was from the lower part of supracondylar line of femur and additional head was from extra articular outer brim of the lateral tibial condyle posteriorly. Tendon of both the 
heads were fused and inserted normally. Nerve supply of both the heads was from nerve to lateral head of gastrocnemius, branch from tibial nerve.

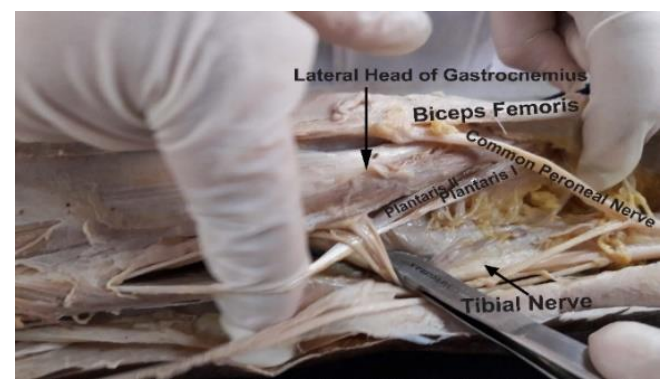

Fig. 2: Double Belly of Plantaris Muscle

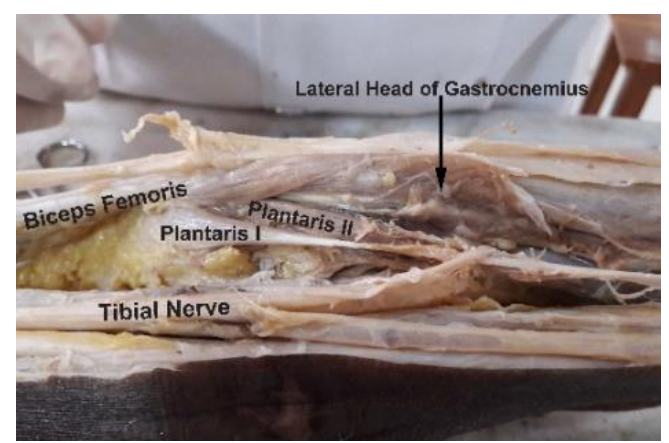

Fig. 3: Double Belly of Plantaris Muscle

In cadaver no. 8 (Fig. 2) Double head of origin of plantaris muscle was observed in left lower limb. One head originated normally from the lower lateral supracondylar line above the origin of lateral head of gastrocnemius, while additional head originated along with the lateral head of gasrtocnemius. Nerve supply of both the heads was from nerve to lateral head of gastrocnemius, branch from tibial nerve. Tendons of both the heads fused and inserted normally along with tendocalcaneus.

No variation in insertion was observed. Tendon of muscle ran on medial side of tendocalcaneus and was either attached to the medial side of calcaneum or was fused with tendocalcaneus.

Variations were noticed in length and width of muscle belly.

\section{Discussion}

Gastrocnemius, soleus and plantaris muscles are collectively referred as triceps surae muscle. Plantaris muscle is vestigial in humans, being absent in about $10 \%$ of individuals. Cruvehiller ${ }^{3}$ was first to describe plantaris as vestigial assuming that as our forefathers have assumed an erect posture and plantaris muscle has lost its original attachment to plantar aponeurosis and has gained a secondary attachment to calcaneum due to special development of calcaneal protuberance. In terms of function, the plantaris muscle acts with the gastrocnemius and is insignificant as either a flexor of the knee, or a plantar flexor of the ankle. It has been thought to be an organ of proprioceptive function for the larger, powerful plantar flexors, as it contains a high density of muscle spindles. ${ }^{4}$

Normally the length of belly of muscle ranges from $7-13 \mathrm{~cm}$ varying highly in size and form .In our study length of muscle belly was found to be in the range of $2.5-14 \mathrm{~cm}$. Average length of tendon was $31.75 \mathrm{~cm}$ which was more on left side $(32.4 \mathrm{~cm})$. Aragao et $\mathrm{al}^{5}$ have reported average length to be $33.26 \mathrm{~cm}$. Najma Mobin $^{6}$ (2016) has observed mean length to be $32.32 \mathrm{~cm}$. Out of 50 lower limbs studied 13 (26\%) showed absence of plantaris muscle which varies with study by Aragao et $\mathrm{al}^{5}$ wherein plantaris muscle was present in all the 20 cases. While in a study on 60 lower limbs by Najma Mobin $^{6}$ (2016) there was absence of plantaris in only two of lower limbs and that also bilaterally in same cadaver. Simpson et $\mathrm{al}^{7}$ has reported rate of absence to be between 7-20\%. In addition in our study we have found double head of origin of plantaris muscle in 2 cadavers. (Fig. 2, 3) Double head of plantaris have been reported by Sawant et al, ${ }^{8}$ Rana et $\mathrm{al}^{9}$ and Srimani et al. ${ }^{10}$ Srimani et $\mathrm{a}^{10}$ have observed a rare course of common tendon of both the head deep to both the heads of gastrocnemius and soleus.

Plantaris muscle has a long and thin tendon which may be mistaken for a nerve. Moreover tendon may fuse superficially with fascia of leg, making it vulnerable for injury. Surgeons operating in posterior compartment of leg must be aware of superficial position of tendon and its resemblance to nerve.

Variations in plantaris muscle in terms of its distinct interdigitations with lateral head of gastrocnemius or having a strong fibrous extension to patella may be responsible for patellofemoral pain syndrome. ${ }^{11}$

Tennis leg, a relatively common clinical condition, can be due to various aetiologies like tear of medial head of gastrocnemius, soleus tear, plantaris tear or a combination. Powell ${ }^{12}$ in 1883 was the first to describe isolated rupture of plantaris to be a cause of tennis leg. Ultrasonographic imaging, MR imaging and surgical exploration have shown that injury to plantaris muscle may occur alone or in association with tear to anterior cruciate ligament, gastrocnemius or soleus muscle .Hamilton ${ }^{13}$ (1997) has surgically confirmed isolated rupture of plantaris muscle to be a cause 
of pain and swelling in calf region. On MR imaging a mass later shown to be benign resolving haematoma by excisional biopsy was found between medial head of gastrocnemius and soleus muscle in this case. A complete tear of plantaris muscle was present without any damage to gastrcnemius and soles muscle. Delgado et $\mathrm{al}^{14}$ has also reported isolated rupture of plantaris muscle to be a cause of tennis leg in $1.4 \%$ of cases out of 141 cases studied by him.

Tendon of plantaris due to its excellent tensile strength has been successfully used as a graft for reconstruction of flexor tendon in hand and anterior talofibular and calcaneofibular ligament of ankle. ${ }^{15}$ It has also been tried for atrioventricular valve repair. ${ }^{16}$

A complete plantaris rupture which usually occurs at myotendinous junction will result in proximal retraction of the muscle and on MR imaging this appear as a mass between popliteus tendon anteriorly and lateral head of gastrocnemius posteriorly. Bianchi et $\mathrm{al}^{17}$ has reported that isolated midsubstance complete tear of plantaris tendon must be differentiated from thrombophlebitis and partial Achilles tendon tears. According to them comparing MRI imaging to ultrasound imaging, later was faster and cheaper.

Though plantaris-regarded as a vestigial muscle, its importance as a cause of tennis leg must be kept in mind in a patient of painful calf syndrome. Moreover, it has been used as a graft in reconstruction surgeries, so variations like double head or absence must be known to the surgeons working in this region.

\section{Conclusion}

Presence or absence and variations of plantaris muscle is not only of academic interest to anatomists but also for clinicians especially orthopaedists, plastic surgeons and radiologists in making clinical diagnosis and imaging of painful calf syndrome.

\section{References}

1. Standring Susan. Gray’s Anatomy. The Anatomical Basis of Clinical Practice. 39th ed. Elsevier Churchill Livingstone, Philadelphia, 2005. pp. 1499-500.

2. Romanes G J: Cunningham's Manual of Practical Anatomy. Vol Upper and lower limbs and Abdomen 15th Ed, 2003

3. Cruveilhier, Jean: Anatomie Descriptive. Tome II. Paris, Bechet June, 1834.

4. Bardeen CR. Development and variation of the nerves and the musculature of the inferior extremity and of the neighbouring regions of the trunk in man. Am J Anat 1906; 6:259-390.
5. Aragao, J. A.; Reis, F. P.; Guerra, D. R. \& Cabral, R. H. The occurrence of the Plantaris muscle and its muscle-tendon relationship in adult human cadavers.Int. J. Morphology., 2010;28(1):255-8.

6. Najma Mobin. Anatomical variations of plantaris muscle: A cadaveric study. Int J Anat Res 2016;4(2):2196-9. DOI: 10.16965/ijar.2016.175

7. Simpson, S. L., Hertzog, M. S. \& Barja, R. H. The plantaris tendon graft: an ultrasound study. J. Hand Surg. [Am]. 1991, 16:708-11.

8. Rana KK, Das S, Verma R. Double plantaris muscle: A cadaveric study with clinical importance. Int J Morphol. 2006, 24(3):495-8.

9. Sawant SP, Shaikh ST, More RM. A rare variation of plantaris muscle. Int J Biol Med Res. 2012;3(4):2437-40.

10. Phalguni Srimani, Rudradev Meyur, Alpana De (Bose), Banani Kundu, Anirban Sadhu.

"Unilateral Variation of Plantaris Muscle - A Case Report". Journal of Evolution of Medical and Dental Sciences 2014; Vol. 3, Issue 03, January 20; Page: 618-22, DOI: 10.14260/JEMDS/2014/1875

11. Freeman AJ, Jacobson NA, Fogg QA. Anatomical variations of the plantaris muscle and a potential role in patellofemoral pain syndrome. Clin Anat. 2008 Mar;21(2):178-81.

12. Powell RW. Lawn tennis leg. Lancet. 1883;2:44.

13. Hamilton W, Klostermeier T, Lim EV, Moulton JS. Surgically Documented Rupture of the Plantaris Muscle: A Case Report and Literature Review. Foot \& Ankle International. 1997; 18(8):522-52.

14. Delgado GJ, Chung CB, Lektrakul N, Azocar P, Botte MJ, Coria D, Bosch E, Resnick D. Tennis Leg: Clinical US Study of 141 Patients and Anatomic Investigation of Four Cadavers with MR Imaging and US. Radiology. 2002; 224:1129.

15. Upasna, Kumar A. Bicipital origin of plantaris muscle - a case report. Int J Anat Var. 2011; 4: $177-9$.

16. Shauhaiber JH, Shauhaiber HH. Plantaris tendon graft for atrioventricular valve repair. A novel hypothetical technique. Tex.

17. Bianchi stefano \& Sailly matthieu \& Molini Lucio Isolated tear of the plantaris tendon: ultrasound and MRI appearance- Skeletal Radiol DOI 10.1007/s00256-010-1076-0 